\title{
La carrera militante de la referencia a Bernard Manin en los movimientos franceses a favor del sorteo*
}

\author{
The militant career of the reference to Bernard Manin in French \\ activism for sortition
}

SAMUEL HAYAT**

\begin{abstract}
Resumen: El libro de Bernard Manin Los principios del gobierno representativo ha sido fundamental para crear un vínculo entre democracia y sorteo, tanto en teoría política como en la esfera militante. Este artículo reconstruye la carrera militante de esta referencia teórica. A pesar de que, en un primer momento, el sorteo fue defendido por reformadores, a partir de 2006 se convertirá en la reivindicación clave de un movimiento ciudadano impulsado por un partidario del "no" al Tratado constitucional europeo: Etienne Chouard. Sin embargo, el libro de Manin tiene para Chouard una función legitimadora y más aún para los militantes que le siguen.

Palabras clave: sorteo, ciudadanismo, Bernard Manin, democracia.
\end{abstract}

\begin{abstract}
Bernard Manin's Principles of representative governement played a crucial role in establishing a link between democracy and sortition, both in political theory and among activists. This article examines the militant career of this reference. While sortition was first promoted by reformers, it became a key demand of a citizen movement led by Etienne Chouard, a supporter of the "No" during the referendum for a Treaty establishing a Constitution for Europe. Nevertheless Manin's book played more of a legitimizing role for Chouard and even more so for his followers.
\end{abstract}

Keywords: sortition, citizenism, Bernard Manin, democracy.

La teoría política francesa fue particularmente receptiva al redescubrimiento, durante la década de los 90 del siglo pasado, del carácter democrático del uso del sorteo en política ${ }^{1}$. Para explicar este hecho, podemos pensar en varias razones. Por una parte, debido a la herencia de Montesquieu y de Rousseau, quienes describen el sorteo como un buen procedimiento

Fecha de recepción: 30/05/2017. Fecha de aceptación: 17/09/2017.

* Este artículo, la traducción al español, a cargo de Francisco Manuel Carballo Rodríguez, y la revisión de la misma, a cargo de Jorge Costa Delgado, se han hecho en el marco del proyecto de I+D: "La recepción de la Filosofía grecorromana en la Filosofía y las Ciencias Humanas en Francia y España desde 1980 hasta la actualidad" (FFI2014-53792-R).

** Responsable de investigación del CNRS en el Centro de estudios y de investigaciones administrativas, políticas y sociales (CERAPS, Lille). samuel.hayat@univ-lille2.fr. Líneas de investigación: la representación política y las revoluciones y los movimientos obreros del siglo XIX. Publicaciones recientes: Quand la République était révolutionnaire. Citoyenneté et représentation en 1848, Editions du Seuil, 2014. "The Revolution of 1848 in the History of French Republicanism”, History of Political Thought, vol. 36, n² 2, 2015, pp. 331-353.

1 Véase por ejemplo: (Rancière, 2005; Sintomer, 2011; Vergne, 2011; Cervera-Marzal \& Dubigeon, 2013). 
democrático. Por otra, debido a la escasa influencia de la llamada teoría realista o mínima de la democracia, inspirada en los textos de Joseph Schumpeter. Cabe destacar, además, el creciente interés por la política antigua y, más concretamente, por la democracia ateniense. Aunque existe otra razón que debemos a Bernard Manin. Este investigador francés introdujo con éxito, en los debates de la ciencia política, la cuestión de la relación entre democracia y sorteo mediante su libro publicado en 1995, Los principios del gobierno representativo, traducido al inglés y al español en 1997 y a partir del año 2000, en alemán, ruso, italiano (Manin, 1996). El hecho de que Bernard Manin forme parte de redes de investigación sobre teoría democrática con un alto grado de internacionalización, sobre todo a partir de su importante artículo seminal sobre la deliberación, ha sido sin duda decisivo para entender el éxito de su libro (Manin, 1987; Przeworski \& Manin, 1999). Pero también debe considerarse la claridad y la fuerza de su argumentación. El libro nos muestra que los regímenes de gobierno representativo, basados en el uso de la elección, se construyeron históricamente contra lo que hasta entonces se llamaba democracia. Esto es, contra la idea de un régimen antiguo que concedía un papel central al sorteo. Los fundadores del gobierno representativo buscaban asegurar mediante la elección la superioridad de los dirigentes sobre el pueblo -pese a ello, para Bernard Manin la elección es un procedimiento intrínsecamente mixto que tiene efectos democráticos y no solo aristocráticos.

Todo ello ha hecho posible que el libro de Bernard Manin tenga un papel fundamental en la teoría democrática en Francia. Pero su recepción no se detuvo en las fronteras de la ciencia política, ni tampoco en las del mundo universitario. Una particularidad de Los principios del gobierno representativo es que ha tenido, junto a la recepción universitaria, una recepción militante ${ }^{2}$. El objetivo de este artículo es estudiar los usos y los efectos del libro de Bernard Manin en los espacios militantes, desde una perspectiva de historia social de las ideas. Lo que se propone, en suma, es reconstruir la "carrera militante" de esta referencia teórica ${ }^{3}$. La idea es captar el contexto, los distintos momentos y los puntos de inflexión en los que aparece la referencia militante al libro de Bernard Manin en Francia. Esta carrera militante se desarrolla, sobre todo, en el seno de un colectivo de un contorno difuso pero que puede calificarse como "ciudadanista", que plantea superar la democracia de partidos mediante la promoción de la participación no partidaria de ciudadanos ordinarios (Ogien \& Laugier, 2014). Este colectivo está compuesto por asociaciones que presentan candidaturas, denominadas de la ciudadanía, a las elecciones locales y que defienden la participación ciudadana y el cambio de la Constitución. Estas experiencias buscan a menudo, mediante referencias a la Antigüedad, en particular a la Atenas democrática, la fuente y la justificación de su crítica a la democracia partidista y a su dispositivo fundamental: la elección. Si bien la referencia a la democracia directa representa para los ciudadanistas un lugar de paso obligado, desde hace una década puede constatarse en estos grupos, al menos en Francia, la referencia más concreta al sorteo como solución, al

2 Sobre las recepciones de Los principios del gobierno representativo puede verse el diálogo entre Antoine Chollet y Bernard Manin, en: "Les postérités des Principes du gouvernement représentatif, une discussion avec Bernard Manin", Participations, en prensa.

3 Mi perspectiva aquí se inscribe en un programa de investigación esbozado por Nicolas Belorgey, Fréderic Chateignier, Mathieu Hauchecorne y Étienne Pénissat (2011) en un número monográfico de revista sobre "la carrera militante de las referencias teóricas". 
mismo tiempo técnica y política, para el proyecto de ciudadanización de la democracia 4 . En ese contexto, el libro de Bernard Manin se ha impuesto como una de las referencias fundamentales, a menudo presente en los textos y en ocasiones en los discursos, de estos militantes ciudadanistas 5 .

Puesto que se trata de una utilización absolutamente paradójica del libro de Bernard Manin, un enfoque en términos de carrera militante de las referencias teóricas está justificado y nos parece necesario. Pese a que el trabajo de Bernard Manin ha jugado en Francia un papel de primer orden en la recuperación del carácter democrático del sorteo, no se trata en ningún caso de una defensa del sorteo frente a la elección. Muy al contrario, el libro propone una defensa razonada del gobierno representativo y de la elección como su dispositivo central. Pero no como el mecanismo democrático por excelencia, sino como el modo de desarrollar una constitución mixta, al mismo tiempo democrática y aristocrática, o más bien democráticamente aristocrática, lo suficientemente flexible para adaptarse a las distintas circunstancias. Pero entonces, ¿cómo ha podido el libro de Bernard Manin imponerse en la justificación de proyectos que representan lo contrario a la intención de su autor? Por otra parte, ¿cuál es el contexto en el que la referencia a Bernard Manin se incorpora al movimiento ciudadanista, a través de qué mediadores, cuál es su temporalidad, qué efectos tiene? Para responder a estas preguntas, en primer lugar presentaremos la militancia por el sorteo antes de la generalización de la referencia a Manin; a continuación nos concentraremos en la figura de Etienne Chouard, el introductor de esta referencia; por último, nos detendremos en los efectos de la referencia a Bernard Manin en el movimiento a favor del sorteo.

\section{Reformar la democracia mediante el sorteo}

El contexto del comienzo de la carrera militante de la referencia a Manin se puede situar a mediados de los años 2000. Concretamente a partir de las movilizaciones contra el Tratado constitucional europeo, que lograron que el proyecto fuese rechazado en el referéndum de mayo de 2005. Sin embargo, la referencia militante al sorteo no había estado completamente fuera del debate público hasta entonces, si bien hay que señalar que era muy minoritaria. Para captar el contexto de la recepción de la obra de Bernard Manin, debemos previamente revisar algunos trabajos militantes que hablaban del sorteo, pero sin hacer referencia a Bernard Manin. En primer lugar, a final de los años 90 surgió un movimiento favorable al uso del sorteo, llamado la "clerocracia", impulsado por François Amanrich, quien publicó en 1999 un ensayo corto titulado La démocratie est morte, vive la clérocratie! ou la clérocratie comme alternative à la démocratie, en una editorial de alcance limitado aunque de prestigio como Barré \& Dayez (Amanrich, 1999). En 2003, Hervé Chaygneaud-Dupuy escribió el libro titulado Des députés tirés au sort. Proposition iconoclaste pour des citoyens législateurs que, en un primer momento, se distribuyó entre un público muy restringido y posteriormente se publicó en Internet (Chaygneaud-Dupuy, 2003). En 2007, esta vez en Bélgica,

4 Sobre esta cuestión pueden verse los trabajos que está realizando Dimitri Courant. Puede verse también (Vergne, 2011, 349-354).

5 Otros trabajos citados habitualmente son: Finley (2003), Blondiaux (2008), Sintomer (2011). 
Robert Grabinszky autopublicó su trabajo Manifeste pour une nouvelle démocratie. Devenir parlementaire : pourquoi pas vous? (Grabinszky, 2007). Estos textos comparten la defensa de la introducción del sorteo en política, según distintos modelos ${ }^{6}$. Los libros carecen de cualquier referencia teórica, salvo unos cuantos artículos de la revista Le Débat ${ }^{7}$, algunos artículos de prensa y, en ocasiones, algunos viejos libros sobre la democracia ateniense solamente Chaygneaud-Dupuy hace referencia a Moses Finley. El libro de Bernard Manin pasó desapercibido para estos autores, a pesar de estar publicado en 1995 y de tener, ya en ese momento, un gran reconocimiento en la teoría política.

Estas obras, además de estar alejadas de las normas convencionales de la escritura académica, comparten algunos rasgos que reflejan su voluntad política. Se trata, por ejemplo, de trabajos muy críticos con la democracia parlamentaria, a la que describen como un régimen caracterizado por "la apropiación del poder y su conservación, a través de pequeños grupos que siempre han utilizado sistemas que les permitieran ser los únicos que pudieran servirse de ellos" (Amanrich, 1999, 8), "una farsa -costosa- destinada a perpetuar el sistema en vigor" (Grabinszky, 2007,33), una "partitocracia" que ha transformado los países en "auténticas repúblicas bananeras, en un gigantesco bananaland" (Grabinszky, 2007, 88), un régimen basado en "la irresponsabilidad de los políticos" (Chaygneaud-Dupuy, 2003, 45) ${ }^{8}$. Contra ese régimen ocupado por una clase política que acapara el poder y que defiende sus propios intereses, los autores proponen hacer entrar a los ciudadanos en política mediante el sorteo. Su propósito es, más allá de algunas diferencias en el tono, devolver el orden a la República, recuperar la adhesión de los ciudadanos al sistema político, "devolver al pueblo aquello que más echa de menos: la fe en sus dirigentes" (Amanrich, 1999, 102), recuperar "la continuidad en la acción de gobierno" (Grabinszky, 2007, 51) y combinando ciudadanos sorteados y expertos independientes, "permitir a los ciudadanos situarse en el centro de la acción pública, implicándose en las decisiones sobre el conjunto de los asuntos importantes" (Chaygneaud-Dupuy, 2003, 2). Estamos, por tanto, muy lejos de una perspectiva de democracia radical. Pese a que la referencia a Atenas se utiliza en ocasiones, aunque casi siempre de pasada, el propósito queda lejos de reflexionar sobre la manera de poner en práctica una democracia directa.

¿Qué ambicionan entonces estos libros? Hervé Chaygneaud-Dupuy nos ofrece una clave describiendo el proceso que le llevó a descubrir y, más tarde, a defender la idea del sorteo de los diputados:

"Hace muchos años que estoy trabajando en el tema del sorteo de los diputados. Desde que otro agitador de ideas, Didier Livio, que en aquel momento colaboraba con un pequeño grupo de "liberales de izquierdas" que trataban de introducir nuevas ideas en el debate político, me preguntó si yo tenía "ideas sobre principios de cambio" en la esfera de la acción pública. La idea surgió de manera espontánea, aunque tenía una genealogía que había olvidado y que recuperé recientemente en mi biblioteca. En 1983 había leído "Le juste pouvoir", el libro de Yves Cannac. Su lectura me marcó

6 Debería añadirse a esta lista a Sizif (1998), a pesar de que el autor pertenece al grupo Jalons -un grupo de humoristas cercanos a Basile de Koch-, lo que invita a pensar que su propuesta es más una provocación que algo que deba tomarse en serio.

7 Revista dirigida a un público culto pero no universitario.

8 Sobre el antiparlamentarismo en Francia, ver: Caron (2013). 
entonces por su clarificador análisis del "poder hegemónico" y por la propuesta de contraponer a ese poder una práctica civil del poder que abriría espacios a la sociedad y reforzaría su capacidad de participación en las responsabilidades públicas. Al volver a abrir ese libro, que había olvidado durante veinte años, me sorprendió encontrar una reflexión prospectiva que hacía referencia explícita al sorteo de los diputados" (Chaygneaud-Dupuy, 2003, 44).

Hervé Chaygneaud-Dupuy era entonces un asesor que organizaba los "Talleres de ciudadanía" con Didier Livio, su jefe, un "agitador de ideas" fundador de Synergence, una empresa de consultoría orientada hacía el desarrollo sostenible, que actualmente forma parte de Deloitte, una gran empresa de consultoría, y antiguo presidente del Centro de jóvenes dirigentes de empresa. Chaygneaud-Dupuy también hace referencia a Gaston Jouffroy, que había publicado un libro de gestión editado por Synergence (Jouffroy, 2007). Se trata, por tanto, de "agitadores de ideas" salidos de la sociedad civil, que leen la revista Le Débat y de un enarca próximo a Chaban-Delmas, Yves Cannac, que organiza talleres de reflexión, etc.

De tal manera que nos encontramos, salvando las distancias, ante lo que Christian Topalov ha llamado una "nebulosa reformadora" (Topalov, 1999). Estos autores son personas ajenas a los distintos campos de profesionales de la producción intelectual, aunque son titulados universitarios. Desarrollan sus competencias en el sector privado, pero están movidos por un espíritu de servicio público que les lleva a investigar sobre las posibilidades de mejora de la democracia. No solo no conocen a Bernard Manin, sino que, en el fondo, no tienen necesidad de ello, como tampoco la tienen de profundizar en el modelo ateniense. Sus propuestas de reforma son autorreferentes -no recurren a argumentos de autoridad- y están dictadas por su buen sentido reformador y por una noción del interés general que se ejerce sin apenas mediaciones, puesto que no está sometido a las reglas que impone la pertenencia a un campo de profesionales del interés general (Bourdieu, 2011). Se puede constatar que esta filiación reformadora del sorteo permanece vigente. Veamos un solo ejemplo, a través del caso de Jean-Luc Wingert. Se trata de un "consultor técnico en el campo de la energía y el desarrollo sostenible"9 que en 2015 publicó Le syndrome de Marie-Antoinette -un libro en el que se promociona la idea de un Senado ciudadano sorteado- y que también es un reformador, no perteneciente a ningún partido, y que en 2005 había publicado un libro sobre el pico máximo de producción de petróleo (Wingert, 2015). Wingert también creó, como había hecho Amanrich, un movimiento para la constitución del Senado ciudadano ${ }^{10}$. Bernard Manin aparece citado en una ocasión en el libro de Jean-Luc Wingert, aunque este no lo haya leído y la referencia provenga del consejo de un amigo universitario ${ }^{11}$. En resumen, la idea del sorteo comienza su carrera militante en Francia sumergida en una nebulosa reformadora, significativamente ajena tanto al mundo universitario como al mundo de la militancia partidista; de tal manera que en 1999, en 2003, en 2007 y en 2016 no se presta ninguna atención al libro de Bernard Manin publicado en 1995.

9 Véase: https://fr.wikipedia.org/wiki/Jean-Luc_Wingert

10 Véase: http://www.senatcitoyen.fr/

11 Entrevista con Jean-Luc Wingert, La Mutinerie, 26 de enero de 2016. 


\section{Etienne Chouard y el descubrimiento de Los principios del gobierno representativo}

¿Cómo llega a ser central la referencia al libro de Bernard Manin y para quién? El punto de inflexión lo constituye un acontecimiento singular: el referéndum francés sobre el Tratado constitucional europeo, que fue ampliamente rechazado el 29 de mayo de 2005. A pesar de lo cual, este resultado se vería alterado en la práctica, ya que lo esencial de las medidas que contenía el proyecto finalmente se impondría mediante el Tratado de Lisboa en 2007 (Lehingue, 2007). Se trata de un momento crucial, al menos, por dos razones. La primera, porque se constata la enorme distancia que separa a los partidos mayoritarios, tanto de izquierdas como de derechas, que hicieron campaña por el sí, de la opinión mayoritaria del país, lo que reforzaría la discusión sobre la desconfianza mutua entre el pueblo y las elites. La segunda, porque se produce una intensa deliberación en el espacio público, combinada, gracias a las transformaciones sociales y técnicas, con la expresión pública de colectivos plurales en nuevos espacios de discusión, sobre todo en Internet, y la intervención de ciudadanos-expertos (Fouetillou, 2007; Cardon \& Granjon, 2013; Pô \& Vanbremeersch, 2015).

Precisamente uno de esos ciudadanos-expertos que se dio a conocer durante la campaña del referéndum sería quien acabaría siendo el militante más importante por el sorteo en Francia. Etienne Chouard se convertiría así en una figura central del campo por el no en el referéndum y en el principal valedor no universitario del libro de Bernard Manin. Este profesor de informática en BTS ${ }^{12}$ publicó en marzo de 2005 un texto contra el tratado europeo que tuvo, en un primer momento, una gran difusión en las redes de la izquierda radical y más tarde también en los grandes medios de comunicación. El texto inspiró también algunos comentarios académicos (Chouard, 2005). Etienne Chouard se situó, en un primer momento, en una posición central en la esfera de la izquierda radical, lo que le obligaría más tarde a modificar su manera de presentarse, así como su relación con el conocimiento. En su texto inicial se presentaba como un simple ciudadano, sin ninguna competencia particular y que no comprendía el proyecto de Constitución. Su argumento central se apoyaba, precisamente, en destacar la complejidad del texto constitucional, lo que, a su juicio, distorsionaba el juego democrático y, en particular, el referéndum. Pero al encontrase, gracias a sus análisis, en una posición de experto, tratará progresivamente de construirse una imagen adaptada a su nueva posición. Lo hará aumentando sus lecturas, más o menos eruditas, y de todo ello informará regularmente a través de su página de Internet. Tras la victoria del no en el referéndum y mientras que los "comités por el no" se debilitan progresivamente, Chouard consolida su posición creando un foro de discusión, el "foro del plan C: por una Constitución escrita por y para los Ciudadanos"13, al mismo tiempo que continúa escribiendo en su página de Internet. Como escribió un periodista, Chouard "se hizo cargo de los huérfanos del no"14, haciéndoles compartir sus lecturas y sus avances en la búsqueda de soluciones y de propuestas.

12 Diploma universitario de técnico superior. El BTS (Brevet de technicien superior) es un diploma profesional impartido por el sistema de enseñanza superior en las universidades y con una duración de dos años (N. del T.).

13 Véase: http://etienne.chouard.free.fr/forum/

14 Véase: http://rue89.nouvelobs.com/rue89-presidentielle/2012/03/26/etienne-chouard-nest-pas-mort-il-soigneles-orphelins-du-non-230208 
Durante ese proceso de adquisición de conocimientos jurídicos y políticos especializados, será cuando Chouard descubra el sorteo y a Bernard Manin. Aunque la cronología de este descubrimiento personal esté muy lejos de ser algo evidente. En una entrevista en la que demuestra su soltura en el ejercicio de ser interrogado por los periodistas, Chouard propone una cronología precisa.

“Este descubrimiento fue algo espectacular para mí. Sucedió en 2005, después del referéndum, justo después de la campaña del referéndum que me hizo despertar (...). Me convertí en un activista, un militante, para intentar después del referéndum... Durante el referéndum se luchaba contra algo, es a lo que yo llamaba entonces una anti-Constitución, y claro, yo... en el momento del referéndum, la tentación de retirarse era grande, de decir, bueno, hemos hecho algo y ahora se acabó. Pero más tarde aquella idea era impensable (...) no se había hecho nada, decir simplemente que no, no es... es muy frustrante. Entonces, durante el verano escribí un texto que titulé "Los grandes principios de una buena Constitución", y traté de pensar en lo que nos faltaba; también había un tipo que me había enviado algo durante la campaña del referéndum, que se llamaba Manifiesto por la verdadera democracia. [...] Lo puse en el montón de las cosas importantes y urgentes. [...] Apareció de nuevo [...] tras el referéndum, [...] pasé una tarde leyendo aquella cosa en la que se hablaba de la democracia ateniense, de Manin, de Hansen y de todos los demás libros que luego se convirtieron en mis libros de cabecera. Todo eso sucedió a principios del verano de 2005"15.

La obra a la que Chouard hace referencia está escrita por André Tolmère. Su Manifiesto por la verdadera democracia tiene características muy distintas a los libros que hemos citado anteriormente. Está firmado bajo un pseudónimo, su tono es mucho más militante y en él se mezclan la denuncia de la oligarquía y la defensa del sorteo, con cuestiones más generales de carácter antisionista y algunas ideas conspirativas, sobre todo a propósito del 11 de septiembre. Inspirado por esta lectura y debido a la sensación de vacío que le provocó el final de la campaña por el referéndum, el sorteo se le presentó a Chouard como el punto de partida necesario para una Constitución democrática. No obstante, tanto en el momento de su descubrimiento, a través de André Tolmère, como más adelante, cuando formula por primera vez su propuesta en su blog o en su foro de discusión, a principios de 2006, todavía no aparece ninguna referencia a Manin. La razón es que André Tolmère, desmintiendo el recuerdo de Chouard, nunca cita a Manin. A pesar de tratarse de un libro denso, lleno de fuentes académicas como Philippe Braud, Jacques Ellul, John Rawls, Rousseau e incluso Mogens Hansen... no está Bernard Manin. Esta ausencia es difícil de comprender, teniendo en cuenta el conocimiento que demuestra tener André Tolmère, pero sobre todo porque pone en duda la cronología propuesta por Etienne Chouard. Considerando este hecho y buscando entre los archivos de su página de Internet, encontramos otras fuentes que pueden explicar el descubrimiento del libro de Bernard Manin: un programa de radio en el que Pierre Rosanvallon habría citado a Manin o el comentario en un blog sobre algunas páginas de El odio a la democracia, de Jacques Rancière, que están dedicadas al sorteo.

15 Entrevista telefónica con Etienne Chouard, del 14 abril de 2016. 
En cualquier caso y a pesar de que su descubrimiento no se produce de la mano de André Tolmère, Los principios del gobierno representativo es el primer libro académico que Chouard lee sobre el sorteo y es el que cita durante sus conferencias, en sus vídeos y en sus intervenciones sobre el tema:

"Rápidamente encargué y comencé a devorar, en este orden, a Manin y a Hansen. Porque fue Manin quien me llevó a leer a Hansen, ¡ojo! [...] De hecho la lectura se prolongó durante meses [...] Yo creo que Bernard Manin, a quien conocí y a quien aprecio mucho, me debe mucho de sus libros (risas). He hablado de él, todo el tiempo, todo el tiempo durante diez años. [...].

Entonces, si usted tuviera que decir un libro que realmente...

Manin, sin duda. Manin es magnífico"16.

Tras la lectura del libro de Manin, Chouard lo cita continuamente. El libro le proporciona una base intelectual y una herramienta de transmisión para su propósito militante. Tal y como él mismo reconoce, aconseja el libro "Inmediatamente, en cuanto alguien me pregunta, [...] forma parte de los cinco libros para el despertar ciudadano: está el de Manin, el de Finley, el de Hansen, Sintomer y... y después otros libros, como Alain, Rousseau. (...) Con Manin, la gente se engancha rápidamente" ${ }^{17}$. Este lugar central del libro de Manin se constata en los textos de Chouard, tanto en los más formales como en aquellos que no lo son tanto. Como por ejemplo en el panfleto titulado "¿Sorteo o elección?", donde escribe en una nota a pie de página: "Es fundamental la lectura del excelente libro Los principios del gobierno representativo de Bernard Manin". En ese mismo panfleto introduce largos extractos de libro, que cita en quince ocasiones en diez páginas ${ }^{18}$. Manin es uno de sus autores favoritos a la hora de aconsejar lecturas, seguido por Hansen, Finley y Sintomer, además de, aunque con menos frecuencia, Rancière, Castoriadis, Rosanvallon, Philippe Braud, Simone Weil, Robert Michels y Jacques Testart. En una entrada de blog, del 4 de noviembre de 2006, a la duda que le plantea un lector sobre el sorteo, Chouard contesta de este modo:

"Le recomiendo, efusiva y fraternalmente, la lectura de un pequeño libro colosal: Los principios del gobierno representativo de Bernard Manin. Es el mejor (aunque no es el único excelente), el más sintético que conozco para comprender con profundidad los retos, las prácticas conocidas y las enormes ventajas del sorteo. Si encuentra usted una sola página aburrida entre las cincuenta primeras, prometo devolverle el dinero :o) Es una obra maestra, inteligente y moderada, que arroja luz sobre cuestiones fundamentales olvidadas; cada párrafo es importante, sin nada de materia grasa, un libro indispensable y prioritario para reflexionar sobre la organización del gobierno en la Ciudad"19.

16 Entrevista telefónica con Etienne Chouard, del 14 abril de 2016.

17 Entrevista telefónica con Etienne Chouard, del 14 abril de 2016.

18 "Tirage au sort ou élection? Démocratie ou aristocratie? Qui est légitime pour faire ce choix de société? Le peuple lui-même ou ses élus?", en: http://etienne.chouard.free.fr/Europe/Tirage_au_sort.pdf

19 Disponible en: http://etienne.chouard.free.fr/Europe/forum/index.php?2006\%2F06\%2F10\%2F43-manifestepour-la-vraie-democratie 
Desde el momento en que descubre el libro de Bernard Manin, Etienne Chouard lo utiliza como herramienta para reforzar la convicción de sus seguidores acerca de su idea: crear una nueva Constitución democrática basada en el sorteo.

\section{Las ambigüedades en la difusión de la referencia a Bernard Manin}

¿Cabría entonces pensar que en Los principios del gobierno representativo se encuentra la referencia académica básica del movimiento militante francés por el sorteo, que se crea alrededor de Etienne Chouard a partir de 2006? Pensar en algo así sería exagerado, al menos, debido a tres razones. En primer lugar, como ya se ha dicho, porque el propio Manin no defiende el sorteo, algo que sorprendió a Chouard cuando lo supo, bastante tarde por cierto:

"Me sorprendió mucho escucharle decir [...] que él prefería la elección. Un poco como Tocqueville [y la democracia]. [...] Cuando alguien describe con acierto la realidad, estando en este mundo, en el cual una parte de la realidad permanece oculta, porque nadie habla del sorteo, nadie, absolutamente nadie, uno tiene la impresión de estar haciendo apología. Porque yo lo he leído realmente... Cada vez que yo, en fin... Las cien primeras páginas, porque... [...] Es verdaderamente apasionante"20.

Para Etienne Chouard, la oposición de Manin al sorteo o, más bien, su preferencia razonada por la elección es compatible con el carácter revelador de su obra. Por lo tanto, Chouard hace un uso parcial de Manin, centrado exclusivamente en los primeros capítulos, que son aquellos dedicados al sorteo. Esta interpretación parcial del libro limita, no cabe duda, la referencia a Manin, pero no la excluye, sino que más bien la orienta. La segunda razón que dificulta una apropiación sustancial de la obra de Manin nos servirá para justificar la afirmación anterior. Hemos visto que la primera lectura de Manin causó una fuerte impresión en Chouard, aunque más que un descubrimiento supuso una confirmación. Pero una vez pasado ese primer momento, Chouard movilizará a Manin, no tanto por lo que escribe, sino por su condición de universitario internacionalmente reconocido. El propio Etienne Chouard lo reconoce:

"A mi juicio, ahora nos apoyamos menos en Manin porque, de algún modo, nos hacemos mayores, ¿no? [...]. En ese sentido, Manin es como una etapa, nos proporcionaba apoyo académico cuando no éramos nada, cuando éramos unos completos amateurs sin ninguna legitimidad ni académica, ni mediática, cuando no éramos nada y nos sirvió de apoyo, algo a lo que agarrarse; nos sirvió de soporte y de referente moral, de autoridad... Pero ya no necesitamos eso. [A pesar de lo cual] Manin, gracias su legitimidad, nos proporciona un excelente respaldo académico"21.

20 Entrevista telefónica con Etienne Chouard, del 14 abril de 2016.

21 Entrevista telefónica con Etienne Chouard, del 14 abril de 2016. 
Por lo tanto, el uso que Chouard hace actualmente de Manin es, fundamentalmente, estratégico. A medida que el movimiento de los "Virus amables" (así es como se llaman a sí mismos los seguidores de Chouard) se hace más autónomo, Etienne Chouard, al que suelen presentar como "profesor de economía y de derecho"22, se establece como una fuente de autoridad en sí mismo. Aún así, la referencia al trabajo de Manin sigue siendo útil a Chouard, sobre todo, en la medida en que suele aparecer con regularidad, desde 2007, mezclado en polémicas sobre su vinculación con algunos personajes de la extrema derecha conspirativa, en particular Thierry Meyssan, Jacques Cheminade, François Asselineau y Alain Soral -son vínculos que Chouard asume en nombre del pluralismo, pero que lo convierten, principalmente entre los antifascistas, en un "personaje confuso", que ayuda a difuminar la división entre izquierda y derecha en beneficio de la extrema derecha ${ }^{23}$. Para Chouard, por lo tanto, poder apoyarse en un universitario como Manin, incluso haciéndole decir lo contrario de lo que defiende en su libro, se ha convertido en un recurso clave.

Vayamos con el tercer límite a la recepción de Manin: cuando se pregunta a los seguidores de Chouard, a medida que nos alejamos más de él, la referencia al autor se hace más imprecisa. Si tomamos como ejemplo a un militante del primer círculo, cuyo pseudónimo es "Wikicrate" - ingeniero en electrónica y uno de los principales responsables del grupo de los "Ciudadanos constituyentes", que forma parte del grupo de los "Virus amables"- tenemos la impresión que su relación con Manin es muy vaga. Al igual que muchos otros simpatizantes, "Wikicrate" descubrió los textos de Chouard durante la campaña del referéndum de mayo de 2005. Al preguntarle por el origen de la recuperación de la idea del sorteo, citará de manera espontánea a Bernard Manin.

"Siempre había entre la gente alguien de ciencias políticas, algún especialista, también los helenistas y todo eso, siempre había alguno, ¿no?, una minoría que conocía esas historias, también hay un profesor de Ciencia Política, Bernard Manin, que hizo, que publicó un artículo, o un libro, qué son los Principios del sistema representativo: una breve historia de la experimentación democrática [sic], no sé, puede que confunda un poco a los autores" 24 .

Aunque cita a Manin, Wikicrate mezcla el título de su libro con el de otro libro de Yves Sintomer. En otro momento, Wikicrate dice haber leído a Manin, aproximadamente en 2011, y que le resultó "a menudo aburrido pero, en cualquier caso, interesante"; tampoco esconde que hace del libro un uso instrumental:

"De alguna manera, su ventaja es que servía para validar las cosas [...] Daba crédito al hecho de que el sorteo fue durante siglos un patrimonio, una técnica que los pueblos utilizaban cuando querían hacer algo democrático y que si se olvidó, fue porque en algún momento los poderosos estuvieron en contra y quisieron hacerla desaparecer de la historia" 25 .

22 Puede verse, por ejemplo, en este video: https://youtu.be/_xleck6ZHks ("La vérité sur le chômage!").

23 Véase: http://www.parasite.antifa-net.fr/les-confusionnistes-qui-favorisent-la-montee-du-fascisme-en-europe/

24 Entrevista con Wikicrate en la concentración de Nuit debout, del 27 de abril de 2016.

25 Entrevista con Wikicrate en la concentración de Nuit debout, del 27 de abril de 2016. 
También es posible encontrar a Manin, junto a otros, entre las lecturas que recomiendan los "Ciudadanos constituyentes", fundamentalmente debido a la influencia de uno de los fundadores de la asociación que, además, es doctorando en ciencia política y trabaja sobre el sorteo ${ }^{26}$.

La relación con el libro de Bernard Manin se hace aún más distante si nos centramos en un grado inferior de responsabilidad, como lo demuestra la entrevista con un militante ordinario por el sorteo. Es el caso de Benoît, que es miembro de la Comisión de Constitución del movimiento Nuit Debout, donde representaba al grupo "Organización de una Asamblea constituyente" en la que milita por la creación de una Asamblea constituyente sorteada. El 27 de abril de 2016, en la plaza de la République en París, ocupada desde hacía un mes por el movimiento Nuit Debout, Benoît se encargaba de una mesa sobre la que había octavillas en defensa del sorteo en las que podía encontrase una referencia a Bernard Manin. A pesar de ello, Benoît no tiene ningún conocimiento directo del libro. Su trayectoria militante le permitió descubrir el sorteo sin necesidad de recurrir a ningún libro. Su interés por la política se despertó cuando tenía 18 o 20 años, alrededor de 2005, aunque durante la entrevista no menciona la campaña por el referéndum que se produjo en aquel momento. Benoît descubrió el sorteo a través de Youtube, con algunos videos de Etienne Chouard que un amigo le había aconsejado y aunque reconoce estar de acuerdo con las ideas de base, también dice estar "un poco menos de acuerdo con el tipo" 27 -en referencia a Chouard. A pesar de ser un militante a favor de el sorteo, nunca ha leído ni artículos ni libros sobre el tema, ni tampoco conoce a Manin.

De manera que, a través de Chouard, de Wikicrate y de Benoît, encontramos tres perfiles que, a pesar de no abarcar todo el conjunto de los militantes por el sorteo, hacen un uso muy desigual de Bernard Manin. Mientras que para Chouard es un autor fundamental al que conoce bien, con quien debate y con quien se ha encontrado personalmente; para Wikicrate, que dice conocer el libro y haberlo leído, Manin y su trabajo sirven para legitimar su causa pero mantiene una relación más distanciada con el politólogo y su obra; por último, Benoît distribuye octavillas en las que el libro de Manin aparece en la bibliografía, aunque reconoce no conocer el libro y tiene como única referencia a Etienne Chouard. Chouard, en definitiva, hace las veces de transmisor del trabajo de Manin, pero no es un especialista que estimule a sus seguidores a estudiar o, al menos, a conocer su trabajo. Lo realmente importante es poder movilizar Los principios del gobierno representativo en la defensa del sorteo como la clave para la refundación democrática.

Para concluir, ¿cómo podemos caracterizar la posición que ocupa la referencia teórica a Los principios del gobierno representativo entre los militantes por el sorteo hoy en Francia? Es evidente que se trata de una referencia que ocupa una posición sin equivalente. Basta constatar que se trata del trabajo contemporáneo más citado en los panfletos, las entrevistas, los vídeos o las páginas de Internet. Chouard cita sistemáticamente el libro en sus textos sobre el sorteo, mientras que los movimientos ciudadanistas vinculados a él hacen suya esa referencia, muy útil para legitimar una parte de su discurso. Sin embargo, salvo aquellos que están muy próximos a Chouard, los militantes por el sorteo utilizan muy poco a Manin.

26 Véase: http://www.lescitoyensconstituants.org/2016/04/15/la-biblio-du-tirage-au-sort/

27 Entrevista con Benoît en la concentración de Nuit debout, del 27 de abril de 2016. 
Los movimientos por la clerocracia, por la demarquía o por la loterocracia ${ }^{28}$, así como otros movimientos ciudadanistas defensores del sorteo en Francia, no hacen referencia a Manin. Como tampoco algunos militantes abiertamente de extrema derecha, como Laurent Louis, que defiende el sorteo en la línea de su compromiso antiparlamentario. ¿Podríamos, por lo tanto, pensar que la carrera militante de la referencia teórica a Manin se encuentra, si no restringida, al menos sí estrechamente limitada a un solo grupo dentro del amplio movimiento ciudadanista? Podemos dudar. Manin es recuperado ampliamente por libros que ofrecen herramientas académicas a los militantes, como los trabajos de Yves Sintomer o más recientemente de David Van Reybrouck. Este último, publicó en 2014 Contra las elecciones. Se trata del libro de un universitario en el que el autor expresa su deuda con Los principios del gobierno representativo, del que dice ser "el libro más importante que he leído para este ensayo" (Reybrouck, 2014, 197). Lo que nos muestra el caso Chouard es, en última instancia, que las apropiaciones militantes de las referencias teóricas están siempre muy influenciadas por un determinado contexto de deliberación, en el que los militantes recurren a fuentes intelectuales para dotarse de argumentos -entre los que destacan, sobre los demás, los argumentos de autoridad. El libro de Bernard Manin, tanto por su capacidad de evocación como por la posición que ocupa su autor, tiene, en este sentido, una innegable fuerza militante. Por ello, permanece como una de las referencias fundamentales para los militantes que tratan de (re)introducir el sorteo en el corazón de la democracia.

\section{Referencias}

Amanrich, François (1999): La démocratie est morte, vive la clérocratie!: ou la clérocratie comme alternative à la démocratie. Barré \& Dayez, París.

Belorgey, Nicolas, Chateignier, Frédéric, Hauchecorne, Mathieu \& Penissat, Étienne (2011): “Théories en milieu militant". Sociétés contemporaines. (81), pp. 5-25.

Blondiaux, Loïc (2008): Le nouvel esprit de la démocratie: actualité de la démocratie participative. Seuil, París.

Bourdieu, Pierre (2011): Sur l'État: cours au Collège de France, 1989-1992. Raisons d'agirSeuil, París.

Cardon, Dominique \& Granjon, Fabien (2013): Médiactivistes. Presses de Sciences Po, París.

Caron, Jean-Claude (2013): "Un mal français? Quelques remarques sur la généalogie de l'antiparlementarisme". Parlement[s], Revue d'histoire politique. (HS 9), pp. 23-34.

Cervera-Marzal, Manuel \& Dubigeon, Yohan (2013): "Démocratie radicale et tirage au sort, Radical democracy and sortition”. Raisons politiques. (50), pp. 157-176.

Chaygneaud-Dupuy, Hervé (2003): Des députés tirés au sort. Proposition iconoclaste pour des citoyens législateurs.

Chouard, Etienne (2005): Une mauvaise Constitution qui révèle un secret cancer de notre démocratie.

Finley, Moses I. (2003) [1973]: Démocratie antique et démocratie moderne. Payot \& Rivages, París.

28 Véase: https://www.facebook.com/clerocratie; http://stochocratie.free.fr; http://lotocratie.com 
Fouetillou, Guilhem (2007): “Le web et le traité constitutionnel européen”. Réseaux. (144), pp. 279-304.

Grabinszky, Robert (2007): Manifeste pour une nouvelle démocratie: devenir parlementaire: pourquoi pas vous? Edilivre-Editions APARIS, París.

Jouffroy, Gaston (2007): Analyse institutionnelle: des outils essentiels pour le management: les concepts et les pratiques au service des managers et des acteurs institutionnels. G. Jouffroy, Pontarlier.

Lehingue, Patrick (2007): "Le Non français au traité constitutionnel européen (mai 2005)". Actes de la recherche en sciences sociales. (166-167), pp. 123-139.

Manin, Bernard (1987): “On Legitimacy and Political Deliberation”. Political Theory. 15 (3), pp. 338-368.

Manin, Bernard (1996): Principes du gouvernement représentatif. Flammarion, París.

Ogien, Albert \& Laugier, Sandra (2014): Le principe démocratie: enquête sur les nouvelles formes $d u$ politique. La Découverte, París.

Pô, Jean-Damien \& Vanbremeersch, Nicolas (2015): "La campagne électorale de 2007 et le débat politique en ligne". Commentaire. (117), pp. 147-155.

Przeworski, Adam; Stokes, Susan Carol \& Manin, Bernard (eds.) (1999): Democracy, accountability and representation. Cambridge university press, Cambridge.

Rancière, Jacques (2005): La haine de la démocratie. La Fabrique, París.

Reybrouck, David Van (2014): Contre les élections. Actes Sud, Arles.

Sintomer, Yves (2011): Petite histoire de l'expérimentation démocratique: tirage au sort et politique d'Athènes à nos jours. la Découverte, París.

Sizif, Roger de (1998): La stochocratie: modeste proposition pour que le peuple de France soit heureusement gouverné grâce à l'instauration d'une sélection politique aléatoire. Les Belles Lettres, París.

Topalov, Christian (1999): Laboratoires du nouveau siècle: la nébuleuse réformatrice et ses réseaux en France, 1880-1914. Civilisations et sociétés, 98. Ecole des hautes études en sciences sociales, París.

Vergne, Antoine (2011): Kleros \& Demos: La théorie du tirage au sort en politique au banc d'essai de la pratique de la Planungszelle et du jury citoyen. Thèse de doctorat en science politique thesis. [Online]. IEP de París / Freie Universität Berlin.

Wingert, Jean-Luc (2015): Le syndrome de Marie-Antoinette: que faire lorsque les élites ont perdu la tête? Les liens qui libèrent, París. 
